\title{
MENGHITUNG PERKALIAN JARI TANGAN DI MI 02 KEMBANG KERANG
}

\author{
Muhammad Munir ${ }^{1}$, Lisnawati ${ }^{2}$, Muh. Tarmizi Tahir ${ }^{3}$, Hijriati Sholehah ${ }^{4}$ \\ ${ }^{1,2,3}$ STAI Darul Kamal NW Kembang Kerang NTB, ${ }^{4}$ STTL Mataram \\ ${ }^{1,2}$ Program Studi Pendidikan Guru Madrasah Ibtidaiyah, ${ }^{3}$ Program Ilmu Al Qur'an dan Tafsir, ${ }^{4}$ Teknik \\ Lingkungan \\ *e-mail: munirmuhammad1991@gmail.com ${ }^{1}$,lisnawai.fajar@gmail.com² ${ }^{2}$ tarmizitahir970@gmail.com³ \\ hijriati.chemist@gmail.com ${ }^{4}$
}

\begin{abstract}
The ability to count is one of the important abilities in everyday life, it can be said that all activities of human life require this ability. this is a separate problem for teachers considering that learning at the primary and secondary education levels has differences where teachers in primary schools must master various materials from all subjects. The training method used is lecture, discussion, practice, and question and answer methods. Based on data, about $83.3 \%$ of teachers are enthusiastic about participating in the training and $16.7 \%$ of teachers who are not very enthusiastic about participating in the training. This shows that PKM activities with multiplication training using fingers are responded well and are in demand by teachers. There are several obstacles related to counting using finger media, namely errors in calculating line segments, distinguishing multiplier numbers and multiplied numbers. Therefore, we hope that teachers will often repeat or practice themselves by looking at the guidelines that have been given so that there are no mistakes in teaching students.
\end{abstract}

\section{Keywords: Counting, Multiplication, Finger}

\begin{abstract}
Abstrak
Kemampuan berhitung merupakan salah satu kemampuan yang penting dalam kehidupan sehari-hari, dapat dikatakan bahwa semua aktivitas kehidupan manusia memerlukan kemampuan ini. Hal ini menjadi permasalahan tersendiri bagi guru-guru mengingat pembelajaran pada jenjang pendidikan dasar dan menengah memiliki perbedaan dimana guru-guru di sekolah dasar harus menguasai berbagai materi dari semua mata pelajaran. Pelatihan menggunakan metode ceramah, diskusi, praktek, dan tanya jawab. keantusiasan guru MI 02 kembang kerang berdasar data, sekitar 83,3\% guru yang semangat mengikuti pelatihan dan $16,7 \%$ guru yang kurang sangat semangat mengikuti pelatihan. Ini menunjukkan kegiatan PKM dengan pelatihan perkalian menggunakan jaritangan direspon baik dan diminati oleh guru. adapun kendala tekait menghitung menggunakan media jaritangan, yaitu kekeliruan menghitung ruas garis, membedakan bilangan pengali dan bilangan yang dikali. Oleh karena itu, kami berharap kepada guru untuk sering mengulang atau praktek sendiri dengan melihat panduan yang sudah diberikan agar tidak terjadi kesalahan dalam mengajarkan siswa.
\end{abstract}




\section{PENDAHULUAN}

Madrasah Ibtidaiyah Swasta (MIS) M1 02 Kembang Kerang merupakan salah satu pendidikan dasar formal di desa Kembang kerang daya. M1 02 Kembang Kerang memiliki tenaga pendidik dan kependidikan yang cukup jika dibandingkan dengan jumlah siwa yang aktif. Tenaga pendidik seluruhnya sarjana S1 sebanyak 13 orang, diantara 13 orang, 3 orang lulusan S1 PGMI dan 10 orang lulusan sarjana S1 PGMI. Berdasarkan data tersebut, tenaga pendidik masih banyak yang belum sesuai dengan kualifikasi S1 PGSD/PGMI, hal ini menjadi permasalahan tersendiri bagi guru-guru mengingat pembelajaran pada jenjang pendidikan dasar dan menengah memiliki perbedaan dimana guru-guru di sekolah dasar harus menguasai berbagai materi dari semua mata pelajaran.

Menurut (Aisyah, 2017) Kemampuan berhitung merupakan salah satu kemampuan yang penting dalam kehidupan sehari-hari, dapat dikatakan bahwa semua aktivitas kehidupan manusia memerlukan kemampuan ini ${ }^{1}$. Pelajaran matematika merupakan keterampilan dasar yang harus dikuasai peserta didik sebelum mempelajari bahan ajar sains. Pada pelajaran matematika di kelas Tinggi (Kelas IV, V, VI) siswa minimal sudah bisa menghitung, menghafal dan memahami perkalian 1 sampai 10. Akan tetapi pada kenyataannya siswa kelas tinggi masih banyak yang belum menghafal perkalian. Oleh karena itu, dengan diadakannya pelatihan menghitung perkalian jari tangan kepada bapak dan ibu guru diharapkan hasil pelatihan tersebut dapat diterapkan kepada siswa. Dengan demikian siswa dapat memahami konsep perkalian dengan menggunakan jari tangan. Jari tangan atau sering disebut dengan jarimatika. Menurut (Payung, 2014) Jarimatika singkatan dari jari dan aritmatika yang adalah berhitung dengan jari tangan ${ }^{2}$. Dengan memanfaatkan jari tangan sebagai media untuk menghitung perkalian merupakan salah satu ide yang kreatif bagi guru.

Atas pertimbangan tersebut kami menganggap perlu memberikan pelatihan kepada guru mengenai keterampilan menghitung menggunakan jari tangan dengan tujuan agar guru memiliki keterampilan menghitung dengan cepat, tepat dan yang paling pentinga dapat di ajarkan kepada siswa konsep menghitung perkalian menggunkan jari tangan. Sasaran pelatihan ini yaitu, guru MI yang menjadi guru kelas dan guru matematika. Oleh karena itu, untuk membantu guru dalam pembelajaran maka kami perlu melakukan pelatihan cara mengajar dalam hal ini materi perkalian. Fokus pelatihan yang akan kami lakukan yaitu pelatihan keterampilan menghitung perkalian dengan jari tangan di MI 02 kembang Kerang. Adapun lokasi pada kegiatan Pengabdian masyarakat adalah M1 02 Kembang Kerang dan sasaran kegiatan ini yaitu guru kelas dan guru matematika yang di M1 02 Kembang Kerang $\mathrm{Hal}$ ini bertujuan agar guru MI 02 Kembang Kerang dapat mempraktekkan disiswa pada saat mengajar.

Guru mempunyai peran yang sangat penting dalam proses pembelajaran. Menurut (Munir, 2020) Guru yang baik adalah guru yang bisa memberikan inovasi dalam setiap

\footnotetext{
${ }^{1}$ Aisyah, N. (2017). Pengembangan Pembelajaran Matematika SD. Ditjen Dikti Depdiknas, h. 6.5

${ }^{2}$ Payung, Z. (2014). Penerapan Jarimatika Untuk Meningkatkan Kecepatan Berhitung Perkalian bilangan Asli Siswa Kelas IV SDN 184 Inpres Ulusalu. Jurnal Keguruan Dan Ilmu Pendidikan, III(1), 470-480, h. 471
} 
pembelajaran. Guru harus bisa memilih dan menggunakan model-model pembelajaran maupun metode yang cocok dengan pendekatan saintifik ${ }^{3}$.

Menurut (Sumirat et al., 2016) "Pembelajaran yang menyenangkan tidak terlepas dari konteks atau makna dari pembelajaran"4. Pembelajaran yang menyenangkan dalam belajar matematika yaitu siswa harus diberikan penguatan terhadap materi yang sudah diberikan agar siswa dapat mengembangkan pengetahuannya sendiri. Menurut (Heruman, 2014) "setiap konsep yang abstrak yang baru dipahami siswa perlu segera diberi penguatan, agar mengenal dan bertahan lama dalam memori siswa" ${ }^{5}$. Jika tidak dilakukan penguatan maka pembelajaran selanjutnya akan membuat siswa menjadi cepat bosan. Siswa merasa bosan disebabkan karena, Proses pembelajaran masih menggunakan pembelajaran secara konvensional yaitu siswa hanya menerima saja tidak ada latihan/praktek.

Menurut (Dewi et al., 2020) Kemampuan adalah kecakapan atau keterampilan yang dimiliki seseorang untuk melakukan beragam tugas dalam suatu pekerjaan ${ }^{6}$. Setiap siswa memiliki kemampuan dalam menyelesaikan tugas. Misalnya Pada pelajaran matematika materi perkalian, untuk menyelesaiakan tugas perkalian siswa diberikan penguatan materi sebagai modal untuk menyelesaikan tugasnya. Oleh karena itu, untuk memudahkan pemahaman siswa terhadap perkalian Guru harus menyiapkan alat dan media untuk meningkatkan pemahaman siswa pada materi yang diajarkan yaitu perkalian. Karena alat dan media sangat penting dalam keberlangsungan pembelajaran. Alat yang digunakan dalam proses pembelajaran merupakan segala sesuatu yang dapat digunakan dalam mencapai tujuan pembelajaran. Sedang menurut (Hamruni, 2009) Alat dapat dibedakan menjadi dua yaitu "alat verbal dan alat bantu verbal" ${ }^{17}$. Alat verbal berupa perintah, larangan, suruhan, dan lain-lain. Sedang kan alat bantu non verbal globe, peta, papan tulis, dan lain-lain. Salah satu media yang cocok dan gratis, salah satunya pemanfaatan jari tangan dalam menghitung perkalian. Pengunaan jari tangan pada perhitungan perkalian dapat membantu siswa dalam berpikir secara abstrak. Jari tangan atau sering disebut dengan jarimatika. Menurut (Payung, 2014) Jarimatika singkatan dari jari dan aritmatika yang adalah berhitung dengan jari tangan ${ }^{8}$. Jarimatika adalah sebuah cara sederhana dan menyenangkan mengajarkan berhitung dasar kepada anak-anak menurut kaidah : Dimulai dengan memahamkan secara benar terlebih dahulu tentang konsep bilangan, lambang bilangan, dan operasi hitung dasar, kemudian mengajarkan cara berhitung dengan jari-jari tangan. Sedangkan (Nasution \& Surya, 2016) menyatakan bahwa Jarimatika adalah suatu teknik atau cara berhitung matematika yang menggunakan alat bantu hitung jari tangan kanan maupun kiri dan bersifat praktis, efisien,

\footnotetext{
${ }^{3}$ Munir, M. (2020). Strategi Guru Dalam Problem Based Learning Untuk Meningkatkan Penalaran Matematika Siswa. De Fermat: Jurnal Pendidikan Matematika, 2(2), 103-108. https://doi.org/10.36277/defermat.v2i2.51, h.103

${ }^{4}$ Sumirat, I., Perkalian, B., Siswa, P., \& Ii, K. (2016). Pengaruh Praktik Jarimatika terhadap Keterampilan Berhitung Perkalian pada Siswa Kelas II SD. Jurnal Kreatif, September, 63-72, h. 64

${ }^{5}$ Heruman. (2014). Model Pembelajaran Matematika di Sekolah Dasar. Rosda, 33

${ }^{6}$ Dewi, V. F., Suryana, Y., \& Hidayat, S. (2020). Pengaruh Penggunaan Jarimatika Terhadap Kemampuan Berhitung Perkalian Peserta Didik Kelas IV Sekolah Dasar. EduBasic Journal: Jurnal Pendidikan Dasar, 2(2), 79-87, h. 80-81

${ }^{7}$ Hamruni. (2009). Strategi dan model-model pembelajaran aktif menyenangkan. Fakultas Tarbiyah UIN Sunan Kalijaga, h. 45

${ }^{8}$ Payung, Z. (2014). Penerapan Jarimatika Untuk Meningkatkan Kecepatan Berhitung Perkalian bilangan Asli Siswa Kelas IV SDN 184 Inpres Ulusalu. Jurnal Keguruan Dan Ilmu Pendidikan, III(1), 470-480, h. 471
} 
cepat serta akurat untuk menghitung operasi aritmatika seperti perkalian ${ }^{9}$. Menurut (Caffriyati \& Lisa, 2015) pembelajaran dengan menggunakan teknik Jarimatika dapat meningkatkan pemahaman operasi perkalian pada mata pelajaran matematika ${ }^{10}$. Untuk menghitung perkalian pada bilangan asli dengan cepat dan tepat, menggunakan jari tangan. Misalnya menghitung $6 \times 7$ perhatikan langkah-langkah berikut ini!

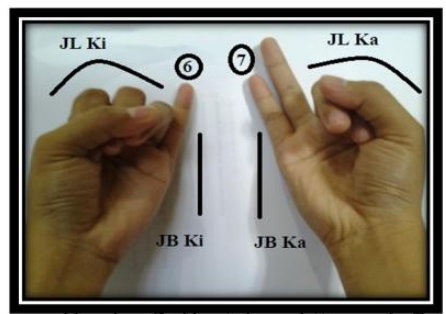

Gambar 1. Contoh Perhitungan $6 \times 7$

a. Formasikan jari tangan kanan nilai 7 dan jari tangan kiri nilai 6 sesuai nilainya, masingmasing jari memiliki nilai.

b. Masing-masing ada dua jenis jari yakni jari yang berdiri (JB) dan jari yang dilipat (JL). Jari yang berdiri sebelah kiri (JB ki) sebagai puluhan (10). Jari yang berdiri sebelah kanan (JB ka) sebagai puluhan (20). Jari yang dilipat sebelah kiri (JL ki) sebagai satuan (4). Jari yang dilipat sebelah kanan (JL ka) sebagai satuan (3).

c. Jumlahkan jari berdiri (JB) sebagai puluhan (30).

d. Kalikan jari dilipat (JL) sebagai satuan (12).

e. Jumlahkan hasil langkah c dengan langkah d

$$
\begin{aligned}
& (J B k i+J B k a)+(J L k i \times J L k a) \\
& =(10+20)+\left(\begin{array}{rrr}
4 & x & 3
\end{array}\right) \\
& =30+ \\
& =42
\end{aligned}
$$

Menurut (Payung, 2014) kelebihan dan kekurangan berhitung menggunakan jari-jari tangan sebagai berikut.

1. Kelebihan Jarimatika

a. Jarimatika memberikan visualisasi proses berhitung.

b. Dapat melatih anak menyeimbangkan otak kiri dan kanan

c. Gerakan jari-jari tangan akan menari minat anak.

d. Jarimatika relatif tidak memberatkan memori otak saat di gunakan.

e. Praktis dan efesien

2. Kelemahan Jarimatika

a. Tidak bisa dipergunakan untuk perkalian satu angka dengan dua angka misalnya $12 \times 7$

b. Jumlah tangan kita terbatas maka operasi matematika yang bisa diseslasaikan juga terbatas

c. Kalau kurang latihan agak lambatcmenghitung dibandingkan sempoa ${ }^{11}$.

\footnotetext{
9 Nasution, tetty K., \& Surya, E. (2016). Penerapan Teknik Jarimatika Dalam Upaya Meningkatkan Kemampuan Operasi Hitung Perkalian Bilangan. UNION: Jurnal Pendidikan Matematika, 4(2), $239-272$.

${ }^{10}$ Caffriyati, R. A., \& Lisa, Y. (2015). Penggunaan Metode Kalkulator Jari Tangan Untuk Meningkatkan Pemahaman Operasi Perkalian Pada Materi Keliling Dan Luas Persegi Dan Persegi Panjang. Jurnal Pendidikan Dasar PerKhasa, 1(1), 27-43, h. 29

${ }^{11}$ Payung, Z. (2014). Penerapan Jarimatika ...
} 
Kegiatan pengabdian ini bertujuan untuk membekali Guru SD/MI cara menghitung perkalian dengan menggunakan jari tangan. Oleh karena itu, para guru tersebut diharapkan mampu mengembangkan keterampilan menghitung menggunakan jari tangan agar dapat diajarkan kembali kepada siswa. Sedangkan Manfaat yang diharapkan dari kegiatan pengabdian ini adalah Memberikan keterampilan kepada guru dalam menghitung perkalian menggunakan jari tangan sehingga dapat di ajarkan kepada siswa dan Sebagai forum untuk bertukar pikiran antara pihak Guru dengan perguruan tinggi dalam hal persiapan bagi guru dalam mengembangkan keterampilan menghitung

\section{METODE}

Metode yang digunakan dalam kegiatan pengabdian ini adalah sosialisasi buku panduan perkalian jari tangan dan pemberian pelatihan dengan beberapa metode yang digunakan. Metode penyampaiannya adalah metode ceramah, diskusi, praktek, dan tanya jawab. Metode ceramah digunakan untuk menjelaskan materi yang ada pada panduan, metode diskusi, praktek dan Tanya jawab digunakan secara bersamaan dalam pelatihan, agar pelatihan berjalan dengan lancar dan guru mudah memahami materinya.

\section{HASIL DAN PEMBAHASAN}

Pelaksanaan kegiatan Pengabdian dilaksanakan di MI 02 Kembang kerang pada tanggal 16 Agustus 2021. Pelaksanaan kegiatan dilakukan secara Sosialisasi buku panduan dan pemberian pelatihan. Sebelum kegiatan pelatihan dilaksanakan terlebih dahulu pemateri menjelasakan materi terkait dengan perkalian, setelah itu dilanjutkan praktek perkalian menggunakan jari tangan dengan dipandu langsung oleh pemateri. Setelah itu, peserta disuruh latihan atau praktek sendiri, dengan contoh yang sudah disediakan pada buku pedoman. Peserta yang ikut dalam kegiatan ini merupakan seluruh guru kelas dan guru mapel yang berada di lingkungan MI 02 Kembang Kerang. MI 02 Kembang kerang mempunyai guru rata-rata lulusan sarjana (S1) meskipun ada yang tidak sesuai dengan kualifikasi keilmuannya. Dalam hal ini, guru setidaknya mengetahui dan memahami metode dan strategi belajar. Seperti pada mata pelajaran matematika banyak siswa yang menganggap mata pelajaran tersebut sulit dan membosankan, hal ini disebabkan karena metode dan strategi dalam proses belajar kurang tepat terutama dalam materi perkalian. Dalam kegiatan pengabdian ini, guru diberikan panduan/pedoman cara menghitung perkalian menggunakan jari tangan pada materi perkalian.

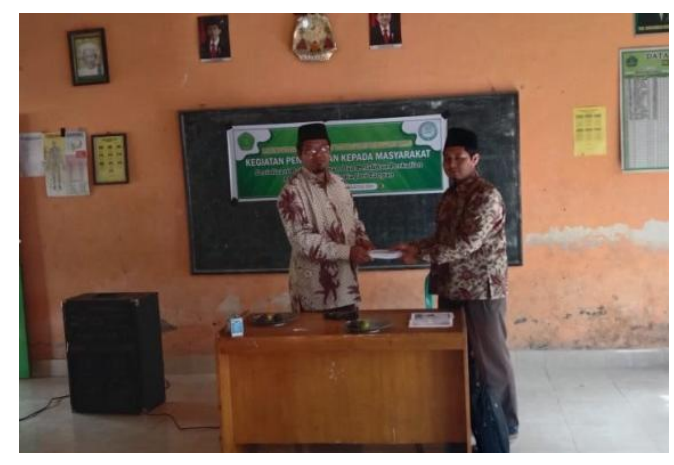

Gambar 2. Penyerahan Buku Pedoman Panduan Perkalian jaritangan 
Selain itu, untuk memperkuat pemahaman guru, kami memberikan pelatihan terkait dengan perkalian jari tangan. Dari kegiatan tersebut, guru dapat memahami cara menggunakan jari tangan pada materi perkalian. Sebagaimana yang tercantum dalam gambar berikut.

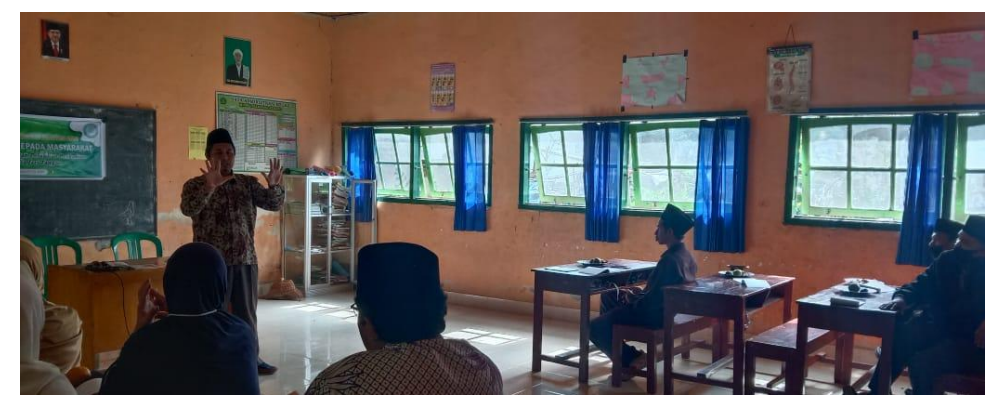

Gambar 3. Pelatihan menghitung perkalian menggunakan media jari tangan

Perkalian menggunakan jari tangan ini sudah lama ada dan sudah banyak yang menggunakan, akan tetapi bagi guru MI 02 Kembang kerang ini merupakan suatu yang baru, sehingga mereka sangat antusias dan semangat untuk bisa memahami perkalian menggunakan media jaritangan. Keantusiasan guru MI 02 kembang kerang dapat dilihat dari semangat mereka dalam mengikuti pelatihan, sekitar $83,3 \%$ guru yang semangat dalam mengikuti pelatihan dan $16,7 \%$ guru yang kurang sangat semangat dalam mengikuti pelatihan. sebagaimana yang ditampilkan pada grafik berikut ini.

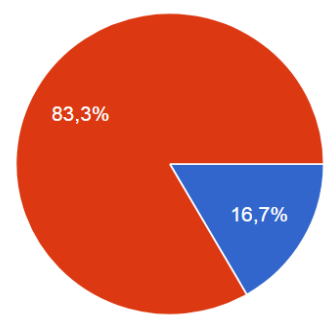

Gambar 4. Grafik antusias dan motivasi

Hal Ini menunjukkan bahwa kegiatan pengabdian kepada masyarakat dengan pelatihan perkalian menggunakan jaritangan sangat direspon baik dan diminati oleh guru. hasil pelaksanaan pelatihan sekitar $66,7 \%$ guru sudah mahir dalam mengaplikasikan jaritangan sebagai media pembelajaran, dan sekitar 33,3\% guru masih butuh bimbingan dan praktek lebih banyak untuk mahir dalam menghitung perkalian menggunakan jari tangan. oleh guru di MI 02 Kembag kerang.

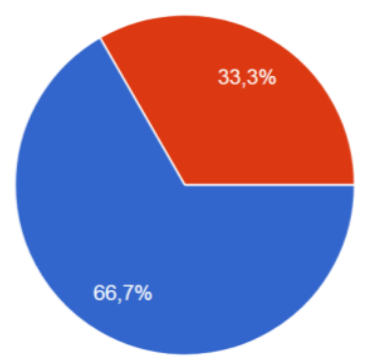

Gambar 5. Tingkat pemahaman guru 
Dari pelaksanaan pengabdian kepada masyarakat, dilihat dari semangat dalam mengikuti pelatihan maka guru mendapatkan pengetahuan baru terkait bagaimana menghitung perkalian menggunakan media jaritangan, guru dapat mengajarkan kepada siswa-siswanya bagaimana cara menghitung perkalian menggunakan media tangan, guru secara tidak langsung mengajarkan siswa berpikir secara abstrak. Ada beberapa kendala tekait menghitung menggunakan media jaritangan, yaitu kekeliruan menghitung ruas garis, membedakan bilangan pengali dan bilangan yang dikali. Oleh karena itu, kami berharap kepada guru untuk sering mengulang atau praktek sendiri dengan melihat panduan yang sudah diberikan agar tidak terjadi kesalahan dalam mengajarkan siswa.

\section{KESIMPULAN}

Dari hasil pengabdian kepada masyarakat yang telah kami lakukan, guru di MI 02 kembang kerang sangat mendukung dan merespon sangat baik terhadap kegiatan ini. Karena melalui kegiatan ini mereka mendapatkan ilmu pengetahuan yang baru. Dengan diadakan pelatihan terkait dengan media jaritangan, diharapkan guru dapat mengajarkan kembali kepada siswa-siswa dalam materi perkalian di madrasah. Meskipun ada beberapa hambatan atau kendala dalam pelatihan diantaranya kekeliruan menghitung ruas garis, membedakan bilangan pengali dan bilangan yang dikali. Oleh karena itu, kami berharap kepada guru untuk sering mengulang atau praktek sendiri agar tidak terjadi kesalahan dalam mengajarkan siswa.

\section{UCAPAN TERIMA KASIH}

Penulis mengucapkan terima kasih kepada Kepala MI 02 Kembang kerang yang telah meberikan kami kesempatan dalam melaksanakan salah satu tri dharma Perguruan Tinggi yaitu Pengabdian kepada Masyarakat di MI 02 Kembang Kerang dan STAI Darul Kamal NW Kembang Kerang yang telah memberi kami dukungan secara financial terhadap pengabdian ini, sehingga pengabdian ini berjalan seseuai dengan rencana.

\section{DAFTAR PUSTAKA}

Aisyah, N. (2017). Pengembangan Pembelajaran Matematika SD. Ditjen Dikti Depdiknas.

Caffriyati, R. A., \& Lisa, Y. (2015). Pengenalan Metode Kalkulator Jari Tangan Untuk Meningkatkan Pemahaman Operasi Perkalian pada Materi keliling dan Luas Persegi dan Persegi Panjang. Jurnal Pendidikan Dasar PerKhasa, 1(1), $27-43$.

Dewi, V. F., Suryana, Y., \& Hidayat, S. (2020). Pengaruh Penggunaan Jarimatika Terhadap Kemampuan Berhitung Perkalian Peserta Didik Kelas IV Sekolah Dasar. EduBasic Journal: Jurnal Pendidikan Dasar, 2(2), 79-87.

Hamruni. (2009). Strategi dan model-model pembelajaran aktif menyenangkan. Fakultas Tarbiyah UIN Sunan Kalijaga.

Heruman. (2014). Model Pembelajaran Matematika di Sekolah Dasar. Rosda.

Munir, M. (2020). Strategi Guru Dalam Problem Based Learning Untuk Meningkatkan Penalaran Matematika Siswa. De Fermat: Jurnal Pendidikan Matematika, 2(2), 103-108. https://doi.org/10.36277/defermat.v2i2.51

Nasution, tetty K., \& Surya, E. (2016). Penerapan Teknik Jarimatika dalam Upaya Meningkatkan Kemampuan Operasi Hitung Perkalian Bilangan. UNION: Jurnal 
Pendidikan Matematika, 4(2), 239-272.

Payung, Z. (2014). Penerapan Jarimatika Untuk Meningkatkan Kecepatan Berhitung Perkalian bilangan Asli Siswa Kelas IV SDN 184 Inpres Ulusalu. Jurnal Keguruan Dan IImu Pendidikan, III (1), 470-480.

Sumirat, I., Perkalian, B., Siswa, P., \& Ii, K. (2016). Pengaruh Praktik Jarimatika terhadap Keterampilan Berhitung Perkalian pada Siswa Kelas II SD. Jurnal Kreatif, September, 6372. 